\title{
CHARACTERISTICS AND SURGICAL OUTCOMES IN VERY ELDERLY PATIENTS ( $\geq 75$ YEARS) WITH RENAL CELL CARCINOMA: DATA FROM THE LATIN AMERICAN RENAL CANCER GROUP
}

\begin{abstract}
Adrián M. Garza-Gangemi ${ }^{1}$, Ricardo A. Castillejos-Molina ${ }^{1}$, Gulllermo Gueglio ${ }^{4}$, Ignacio P. Tobia-Gonzalez ${ }^{4}$, Alberto M. Jurado ${ }^{4}$, luis Meza-Montoya ${ }^{5}$, Carlos H. Scorticati ${ }^{6}$, Walter

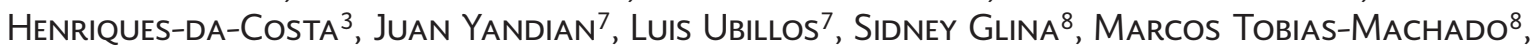
Oscar Rodríguez-Faba ${ }^{9}$, Carlos Ameri ${ }^{10}$, Alejandro Nolazco ${ }^{11}$, Pablo Martinez ${ }^{11}$, Gustavo Franco Carvalhal ${ }^{12}$, Ruben G. Bengio ${ }^{13}$, Leandro Cristian Arribillaga ${ }^{13}$, Raúl Langenhin ${ }^{14}$ Diego Muguruza ${ }^{14}$, José G. Campos-Salcedo ${ }^{15}$, Edgar I. Bravo-Castro ${ }^{15}$, Pablo A. Mingote ${ }^{16}$, Nicolás Ginestar ${ }^{16}$, ana M. Autran-Gomez ${ }^{17}$, Roberto Puente ${ }^{7}$, Ricardo Decia ${ }^{7}$, Gustavo Cardoso-Guimarães ${ }^{3}$, Joan Palou-Redorta9 ${ }^{9}$, Diego Abreu-Clavijo², Stenio de-Cassio-Zequi ${ }^{3}$, and Francisco T. Rodriguez-Covarrubias ${ }^{1 *}$, on behalf of the Latin American Renal Cancer Group (LARCG)

${ }^{1}$ Instituto Nacional de Ciencias Médicas y Nutrición Salvador Zubirán, Mexico City, Mexico; ${ }^{2}$ Hospital Pasteur, Montevideo, Uruguay; ${ }^{3}$ A.C. Camargo Cancer Center, Sao Paulo, Brazil; ${ }^{4}$ Hospital Italiano, Buenos Aires, Argentina; ${ }^{5}$ Instituto Nacional de Enfermedades Neoplásicas, Lima, Peru; ${ }^{6}$ Hospital de Clínicas, Buenos Aires, Argentina; ${ }^{7}$ Hospital de Clínicas, Montevideo, Uruguay; ${ }^{8}$ Escuela de Medicina ABC, Sao Paulo, Brazil; ${ }^{9}$ Fundación Puigvert, Barcelona, Spain; ${ }^{10}$ Hospital Alemán, Buenos Aires, Argentina; ${ }^{11}$ Hospital Británico, Buenos Aires, Argentina; ${ }^{12}$ School of Medicine, Pontifícia Universidade Católica do Rio Grande do Sul (PUCRS), Porto Alegre, Brazil; ${ }^{13}$ Clínica Profesor Bengio, Cordoba, Argentina; ${ }^{14}$ Corporación Médica de Paysandú (COMEPA), Paysandu, Uruguay; ${ }^{15}$ Hospital Central Militar, Mexico City, Mexico; ${ }^{16}$ Policlinico Neuquén, Neuquén, Argentina; ${ }^{17}$ Hospital Fundación Jiménez Díaz, Madrid, Spain
\end{abstract}

\section{ABSTRACT}

Background: The incidence of renal cell carcinoma (RCC) is increasing globally due to an aging population and widespread use of imaging studies. Objective: The aim of this study was to describe the characteristics and perioperative outcomes of RCC surgery in very elderly patients (VEP), $\geq 75$ years of age. Methods: This is a retrospective comparative study of 3656 patients who underwent the treatment for RCC from 1990 to 2015 in 28 centers from eight Latin American countries. We compared baseline characteristics as well as clinical and perioperative outcomes according to age groups ( $<75$ vs. $\geq 75$ years). Surgical complications were classified with the Clavien-Dindo score. We performed logistic regression analysis to identify factors associated with perioperative complications. Results: There were 410 VEP patients (11.2\%). On bivariate analysis, VEP had a lower body mass index $(p<0.01$ ) and higher ASA score (ASA $>2$ in $26.3 \%$ vs. $12.4 \%, p<0.01$ ). There was no difference in performance status and clinical stage between the study groups. There were no differences in surgical margins, estimated blood loss

*Corresponding author:

Francisco T. Rodriguez-Covarrubias

E-mail: frodriguez.covarrubias@gmail.com
Received for publication: 06-02-2020

Approved for publication: 10-04-2020

DOI: $10.24875 /$ RIC.20000018

0034-8376 / (C) 2020 Revista de Investigación Clínica. Published by Permanyer. This is an open access article under the CC BY-NC-ND license (http://creativecommons.org/licenses/by-nc-nd/4.0/). 
$(E B L)$, complication, and mortality rates $(1.3 \%$ vs. $0.4 \%, p=0.17)$. On multivariate regression analysis, age $\geq 75$ years (odds ratio [OR] 2.33, p < 0.01), EBL $\geq 500 \mathrm{cc}(\mathrm{OR} 3.34, \mathrm{p}<0.01$ ), and $>$ pT2 stage (OR 1.63, p $=0.04$ ) were independently associated with perioperative complications. Conclusions: Surgical resection of RCC was safe and successful in VEP. Age $\geq 75$ years was independently associated with 30-day perioperative complications. However, the vast majority were low-grade complications. Age alone should not guide decision-making in these patients, and treatment must be tailored according to performance status and severity of comorbidities. (REV INVEST CLIN. 2020;72(5):308-15)

Key words: Kidney cancer. Elderly. Nephrectomy. Latin America. Surgical Complications. Surgical outcomes.

\section{INTRODUCTION}

Genitourinary malignancies represent a significant public health problem, particularly in developing countries were up to $52 \%$ of all genitourinary cancer deaths occur ${ }^{1}$. In the most recent compilation of data on population-based cancer occurrence, the American Cancer Society estimated that kidney and renal pelvis tumors account for the $6^{\text {th }}$ most common estimated new cancer cases in men (5\%) and the $8^{\text {th }}$ in women (3\%) in the United States ${ }^{2}$ The World Health Organization estimated that by 2018 , from the total combined cancer data, kidney tumors were responsible for 403,262 (2.2\%) estimated new cancer cases and $175,098(1.8 \%)$ cancer deaths in the world. Furthermore, the worldwide age standardized rate (per 100,000 persons per year) for new cases of kidney cancer was 6.0 for men and 3.1 for women, while in low or medium human development index regions, it was 1.8 for men and 1.1 for women ${ }^{3}$. In addition, it has been recently demonstrated that over the most recent 10-year period, the greatest increase in renal cell carcinoma (RCC) incidence occurred in Central and South America, where the average annual percentage change ranged from $3.0 \%$ to $6.8 \%$ in men and $2.5 \%$ to $6.4 \%$ in women ${ }^{4}$.

Due to increasing life expectancy, the number of incident cases of RCC will continue to grow and an increasing proportion of patients aged 75 or older will be ultimately diagnosed with renal cancer and will be considered for active treatment. Despite technological and pharmacological developments, surgery is the cornerstone for the management of most localized (T1/T2) and locally advanced (T3) tumors. Nonetheless, the benefit of this strategy is unclear for elder patients, particularly for frail individuals at higher risk of surgical complications. Guzzo et al. reported an overall complication rate of $22.6 \%$ and $0 \%$ mortality rate in a cohort of 115 patients $>75$ years of age who underwent laparoscopic renal surgery in the United States ${ }^{5}$.

We have previously described our surgical experience in a small cohort of elderly patients with RCC showing that surgery appears to be safe in properly selected cases $^{6}$. To the best of our knowledge, larger reports coming from Latin America are scarce. Therefore, our objective was to compare clinical characteristics and perioperative outcomes of patients 75 years or older with their younger counterparts treated surgically for $\mathrm{RCC}$ in Latin America.

\section{METHODS}

This is a retrospective comparative study of the database of patients with renal tumors from the Latin American Renal Cancer Group (LARCG) ${ }^{7}$. It comprised data from 3656 patients who underwent surgery for RCC from 1990 to 2015 in 28 centers from eight Latin American countries. This study was approved by the corresponding Review Board of each institution. For this study, baseline characteristics as well as clinical and perioperative outcomes according to age groups ( $<75$ years vs. $\geq 75$ years) were compared. We arbitrarily defined very elderly patients (VEP) as those 75 years or older due to RCC epidemiology trends. Patients who did not undergo surgical treatment were excluded from this study. Variables analyzed included sex, age, renal function, comorbidities, eastern cooperative oncology group performance status, tumor stage, clinical stage (using the American Joint Committee on Cancer tumor-node-metastasis 8th edition staging system), type of surgery, estimated blood loss (EBL), length of hospital stay (LOS), and perioperative complications ${ }^{8}$. Surgical complications were classified according to the Clavien-Dindo classification?. Major complications were defined as ClavienDindo $>$ II. 
Table 1. Baseline characteristics between the study groups

\begin{tabular}{|c|c|c|c|}
\hline & $<75$ year old $(\%)$ & $\geq 75(\%)$ & p-value \\
\hline Sex & & & 0.99 \\
\hline Male & $2121(65.4)$ & $268(65.4)$ & \\
\hline Female & $1123(34.6)$ & $142(34.6)$ & \\
\hline BMI $\left(\mathrm{kg} / \mathrm{m}^{2}\right)$ & $28.1 \pm 5.4$ & $26.7 \pm 4.2$ & 0.01 \\
\hline Smoking status & & & 0.01 \\
\hline Active smoker & $228(11.3)$ & $25(8.7)$ & \\
\hline Ex-smoker & $699(34.7)$ & $76(26.7)$ & \\
\hline Non-smoker & $1087(54)$ & $184(64.6)$ & \\
\hline Hypertension & & & $<0.01$ \\
\hline Yes & $436(13.4)$ & $91(22.2)$ & \\
\hline No & $2810(86.6)$ & $319(77.8)$ & \\
\hline ECOG & & & 0.12 \\
\hline ECOG 0-1 & $1822(96.2)$ & $246(94.3)$ & \\
\hline ECOG $>1$ & $71(3.8)$ & $15(5.7)$ & \\
\hline ASA & & & 0.01 \\
\hline ASA $1-2$ & $2263(84.2)$ & $232(64.8)$ & \\
\hline ASA $>2$ & $426(15.8)$ & $126(35.2)$ & \\
\hline Signs and symptoms at diagnosis & & & 0.78 \\
\hline Yes & $1667(61.6)$ & $218(60.9)$ & \\
\hline No & $1037(38.4)$ & $140(39.1)$ & \\
\hline Clinical stage & & & 0.57 \\
\hline CS I & $1234(60.5)$ & 151 (59) & \\
\hline CS II & $324(15.9)$ & $42(16.4)$ & \\
\hline CS III & $328(16.1)$ & $48(18.8)$ & \\
\hline CS IV & $154(7.5)$ & $15(5.8)$ & \\
\hline
\end{tabular}

BMI: body mass index; ECOG: Eastern Cooperative Oncology Group.

Statistical analysis was performed using the SPSS 20.0 for IBM. For descriptive statistics, we used central tendency measures such as mean or median. Standard deviation or interquartile range and range were used as dispersion descriptive measures. Bivariate analysis was performed using paired samples test by t-test while non-parametric variables were compared with Mann-Whitney U-test. Proportions were compared using Chi-square test. Binary logistic regression analysis was performed to identify independent risk factors associated with perioperative outcomes and complications. Any $\mathrm{p} \leq 0.05$ or $5 \%$ were considered as statistically significant for a twotied distribution.

\section{RESULTS}

Baseline patient characteristics between the study groups are summarized in Table 1 . Four-hundred and ten patients ( $11.2 \%$ ) were $\geq 75$ years old compared to $3246(88.8 \%)$ patients who were $<75$ years old. 
Table 2. Comparison of pathological characteristics between the study groups

\begin{tabular}{|c|c|c|c|}
\hline & $<75$ year old $(\%)$ & $\geq 75(\%)$ & p-value \\
\hline Histology & & & 0.01 \\
\hline Clear cell & $1785(55)$ & $268(65.4)$ & \\
\hline Other & $1461(45)$ & $142(34.6)$ & \\
\hline Fuhrman & & & 0.95 \\
\hline Low grade & $1359(66.8)$ & $184(66.7)$ & \\
\hline High grade & $674(33.2)$ & $92(33.3)$ & \\
\hline pT stage & & & 0.20 \\
\hline pT1-T2 & $2142(79.8)$ & $266(76.9)$ & \\
\hline рT3-T4 & $541(20.2)$ & $80(23.1)$ & \\
\hline pTumor size $(\mathrm{cm})$ & $5.0 \pm 4.7$ & $5.2 \pm 4.5$ & 0.33 \\
\hline Multifocality & & & 0.42 \\
\hline Yes & $130(5.1)$ & $23(6.5)$ & \\
\hline No & 2477 (94.9) & $331(93.5)$ & \\
\hline $\mathrm{pN}$ & & & 0.78 \\
\hline pNO & $1710(94.5)$ & $208(95)$ & \\
\hline $\mathrm{pN} 1$ & $99(5.5)$ & $11(5.0)$ & \\
\hline pM & & & 0.99 \\
\hline pMo & $1670(90.8)$ & $216(90.8)$ & \\
\hline pM1 & $170(9.2)$ & $22(9.2)$ & \\
\hline
\end{tabular}

The median follow-up was 21.4 months. On bivariate analysis, patients $<75$ years had a higher body mass index and had more active smokers. On the other hand, older patients $\geq 75$ years had more hypertension and a higher ASA score. There were no differences in signs and symptoms at diagnosis and performance status between the study groups.

There were no differences regarding clinical stage, $\mathrm{pT}$ stage, pathologic tumor size, Fuhrman grade, multifocality, $\mathrm{pN}$, or pM between the study groups (Table 2). However, clear cell histology was far more frequent in the VEP (65.4\% vs. 55\%, p < 0.01). Tumor complexity assessment information was not the focus of our study and was not analyzed.

The laparoscopic approach (44.4\% vs. $37.4 \%, p<0.02)$ and radical nephrectomy ( $72.2 \%$ vs. $57.9 \%, p<0.01$ ) were far more commonly performed in VEP. Surgical and perioperative characteristics are listed in Table
3. There were no differences in surgical margin status, lymph node dissection, EBL, and complication rates. Major complication rates, defined as ClavienDindo Grade >II, were also similar between the study groups ( $5.0 \%$ vs. $4.2 \%$ in VEP, $p=0.59$ ). Perioperative mortality was also similar between the study groups $(0.4 \%$ vs. $1.4 \%$ in VEP, $p=0.85)$. LOS was slightly longer in older patients ( $4 \pm 4$ vs. $4 \pm 3$ days, $p<0.01$ ). Subgroup analysis among patients treated with partial nephrectomy was performed, and no differences were observed with regard to total complication rates between the study groups ( $p=0.99$, Table 4). No perioperative deaths were registered among those 75 years or older who underwent partial nephrectomy.

On our multivariate logistic regression analysis, EBL $\geq 500$ cc (odds ratio [OR] 3.34, Cl 2.23-4.99), age $\geq 75$ years (OR 2.33, $\mathrm{Cl} 1.29-4.21$ ), open surgery (OR 2.52, Cl 1.70-3.77), and > pT2 stage (OR 1.63, 
Table 3. Surgical and perioperative characteristics between the study groups

\begin{tabular}{|c|c|c|c|}
\hline & $<75$ year old $(\%)$ & $\geq 75(\%)$ & $\mathrm{p}$-value \\
\hline Surgical approach & & & 0.02 \\
\hline Laparoscopic & $1164(37.4)$ & $176(44.5)$ & \\
\hline RALP & $24(0.7)$ & $4(1.0)$ & \\
\hline Open & $1927(61.9)$ & $216(54.5)$ & \\
\hline Primary tumor treatment & & & 0.01 \\
\hline Radical nephrectomy & $1878(57.9)$ & $296(72.2)$ & \\
\hline Partial nephrectomy & $1368(42.1)$ & $114(27.8)$ & \\
\hline Surgical time (min) & $174 \pm 88$ & $164 \pm 75$ & 0.01 \\
\hline $\mathrm{EBL}(\mathrm{mL})$ & $455 \pm 675$ & $416 \pm 473$ & 0.37 \\
\hline Surgical margins & & & 0.77 \\
\hline Positive & $102(3.4)$ & $12(3.1)$ & \\
\hline Negative & $2885(96.6)$ & $371(96.9)$ & \\
\hline Blood transfusion & & & 0.28 \\
\hline Yes & $455(17.5)$ & $66(19.9)$ & \\
\hline No & $2140(82.5)$ & $265(80.1)$ & \\
\hline Lymphadenectomy & & & 0.06 \\
\hline Yes & $532(19.1)$ & $47(12.9)$ & \\
\hline No & $2250(80.9)$ & $318(87.1)$ & \\
\hline Clavien-Dindo & & & 0.17 \\
\hline None & $572(43.7)$ & $96(44.7)$ & \\
\hline Clavien I-II & $670(51.2)$ & $110(51.2)$ & \\
\hline Clavien III-IV & $61(4.7)$ & $6(2.8)$ & \\
\hline Clavien V & $5(0.4)$ & $3(1.3)$ & \\
\hline Length of stay (days) & $4 \pm 3$ & $4 \pm 4$ & 0.01 \\
\hline
\end{tabular}

EBL: estimated blood loss.

Cl 1.02-2.59, $\mathrm{p}<0.04$ ) were associated with 30-day perioperative complications following surgical treatment for RCC (Table 5).

\section{DISCUSSION}

In the past decade, an increase in the incidence of RCC has been detected in most countries, particularly in Latin American populations for both men and women ${ }^{4}$. This is probably due to the widespread use of abdominal imaging studies for other diagnostic purposes. Nevertheless, while mortality trends have been steady or declining in high-income countries, they have remained unchanged or even increased in Latin America ${ }^{4}$.

Although the treatment of choice for localized renal masses should be individualized, surgical resection (including nephron-sparing surgery [NSS]) is still considered the standard of care for organ-confined disease $^{10}$. In experienced hands, NSS is an excellent alternative for patients with small renal masses (SRM), with oncological equivalence and better preservation 
Table 4. Comparison of complication rates following partial nephrectomy between the study groups

\begin{tabular}{lccc}
\hline Clavien-Dindo & $<75$ year old $(\%)$ & $\geq 75(\%)$ & p-value \\
\hline None & $200(45.1)$ & $20(45.5)$ & 0.99 \\
Clavien I-II & $222(50.1)$ & $22(50.0)$ & $2(4.5)$ \\
Clavien III-IV & $20(4.6)$ & $0(0)$ & \\
Clavien V & $1(0.2)$ & \\
\hline
\end{tabular}

Table 5. Independent risk factors for 30-day perioperative complications following primary treatment

\begin{tabular}{lccc}
\hline Variable & OR & Cl & p-value \\
\hline Univariate & & & 0.75 \\
Age $\geq 75$ years & 1.05 & $0.77-1.42$ & 0.01 \\
EBL $\geq 500$ & 5.33 & $4.07-6.97$ & 0.03 \\
BMI $\geq 30 \mathrm{~kg} / \mathrm{m}^{2}$ & 1.44 & $1.04-1.98$ & 0.13 \\
Partial nephrectomy* & 0.85 & $0.68-1.05$ & 0.01 \\
$>$ pT2 stage & 1.89 & $1.44-2.47$ & 0.01 \\
Open Surgery** & 1.67 & $1.34-2.08$ & \\
Multivariate & & & 0.01 \\
Age $\geq 75$ years & 2.33 & $1.29-4.21$ & $<0.01$ \\
EBL $\geq 500$ & 3.34 & $2.23-4.98$ & 0.07 \\
BMI $\geq 30$ kg/m ${ }^{2}$ & 1.50 & $0.97-2.3$ & 0.04 \\
$>$ pT2 stage & 1.63 & $1.02-2.59$ & $<0.01$ \\
Open surgery** & 2.52 & $1.70-3.77$ & \\
\hline
\end{tabular}

*Radical nephrectomy.

**Minimally invasive surgery.

EBL: estimated blood loss; OR: odds ratio; BMI: body mass index.

of renal function when compared to radical nephrectomy ${ }^{11}$.

Active surveillance (AS) for SRM has gained popularity worldwide since large cohorts have demonstrated that adherent patients have low risk of metastasis (1-2\%) at a median of 2-year follow-up ${ }^{12}$. These results are encouraging and AS must be considered an alternative in the VEP that is a poor surgical candidate.

Nonetheless, the optimal treatment option in the VEP is debatable, to say the least. An adequate general and geriatric evaluation by a multidisciplinary team may provide additional insight for deciding the optimal treatment in this patient population ${ }^{13}$. A large retrospective study of 537 patients demonstrated that active treatment in patients aged $\geq 75$ years with clinical T1 renal cancer was not associated with improved overall survival and that nephrectomy accelerated renal dysfunction ${ }^{14}$. A recent study of 115 octogenarian patients observed no differences in survival between AS, NSS, and radical nephrectomy for $\mathrm{SRM}^{15}$. However, AS may be inadequate in healthy elderly patients and surgical resection should always be considered in selected individuals because at least 20\% of SRM are considered to be potentially aggressive cancers $^{16}$.

Despite the previous findings, the surgical modality of choice (RN vs. NSS) for localized renal masses in 
elderly patient is still unclear. In this study, we observed that while patients 75 years or older had higher ASA scores (ASA >2) and larger tumors, they did not have higher 30-day total complication rate. A recent study where a propensity score analysis of surgical, functional, and oncologic outcomes was performed between 613 patients over 75 years of age compared to matched controls who underwent partial versus radical nephrectomy, found that partial nephrectomy in elderly patients with localized tumors did not compromise oncologic outcomes and allowed better functional preservation compared to radical nephrectomy during a 3-year follow-up. However, they reported a higher overall complication rate in the partial nephrectomy group ( $33 \%$ vs. $25 \%, p=0.01)^{17}$. In our study, partial nephrectomy was performed less commonly in older patients and, on subgroup analysis, there were no differences in complication rates between the study groups. Moreover, long-term renal function was not analyzed in our database. The laparoscopic approach was more common in this subgroup, with no differences in EBL and blood transfusion rates. Surgical time was shorter in VEP, and a possible explanation for this is that more patients underwent radical nephrectomy. On the other hand, LOS was slightly higher in VEP $(p<0.01)$. Interestingly, in our bivariate analysis, VEP did not have greater perioperative complications; however, in our sparse multivariate model, the variables associated with 30day perioperative complications (Clavien-Dindo Grade $\mathrm{I}-\mathrm{V}$ ) following surgery were $\mathrm{EBL} \geq 500 \mathrm{cc}$, open surgery, age $\geq 75$ years, and $>$ pT 2 stage. Of greater importance, in our multivariate logistic regression analysis, age $\geq 75$ years was not associated (OR 1.22, $\mathrm{Cl} 0.60-2.48, \mathrm{p}=0.59$ ) with greater major complications (Clavien-Dindo $>$ II).

The main limitations of this study are its retrospective nature and the missing data that are intrinsic to multicenter databases such as LARCG. LARCG, however, is the first Latin American effort to create a multinational patient database for patients with RCC, and we believe that these results are clinically useful in our population. Larger prospective studies should be conducted to further address this issue.

The higher perioperative complication rates and the fact that renal function benefit after NSS is seen throughout many years of follow-up may make this surgical approach for elderly patient unappealing to some surgeons, and this is possibly the reason more of these patients were treated with radical nephrectomy in our cohort. However, our data suggest that there is no difference in perioperative complication rates of NSS between the study groups. An et al. reported similar perioperative outcomes and further demonstrated that NSS was associated with better preservation of renal function and equivalent overall and cancer-specific survival between modalities ${ }^{18}$. Thus, in countries, where there is limited experience with minimally invasive ablative techniques or if clinical follow-up may be a concern, we recommend surgical resection (NSS in experienced hands) as primary treatment in physically fit elderly patients.

Surgical resection of RCC is safe and successful in properly selected VEPs. Age $\geq 75$ years was an independent risk factor associated with any 30-day perioperative complications following surgical treatment for RCC. However, perioperative outcomes, most importantly major complication and mortality rates, are similar to their younger counterparts. Age alone should not guide decision making in these patients, and treatment must be tailored according to performance status and severity of other comorbidities.

\section{ACKNOWLEDGMENTS}

The authors would like to thank Dr. Carolina Cauduro and Dr. Pablo M. Barrios from Pontifícia Universidade Católica do Rio Grande do Sul (PUCRS), School of Medicine, Porto Alegre, Brazil, for their support in recollecting data.

These results were presented at the American Urological Association's (AUA) 2018 Annual Meeting in San Francisco, California.

This is a retrospective study of a large database of patients from Latin America. This study was IRB approved at each institution.

\section{REFERENCES}

1. Greiman AK, Rosoff JS, Prasad SM. Association of human development index with global bladder, kidney, prostate and testis cancer incidence and mortality. BJU Int. 2017;120: 799-807.

2. Sieger R, Miller K, Jemal A. Cancer statistics, 2020. CA Cancer J Clin. 2020;70:7-30. 
3. Bray F, Ferlay J, Soerjomataram I, Siegel RL, Torre LA, Jemal A Global cancer statistics 2018: globocan estimates of incidence and mortality worldwide for 36 cancers in 185 countries. CA Cancer J Clin. 2018;68:394-424.

4. Znaor A, Lortet-Tieulent J, Laversanne M, Jemal A, Bray F. International variations and trends in renal cell carcinoma incidence and mortality. Eur Urol. 2015;67:519-30.

5. Guzzo TJ, Allaf ME, Pierorazio PM, Miller D, McNeil BK, Kavoussi $L R$, et al. Perioperative outcomes of elderly patients undergoing laparoscopic renal procedures. Urology. 2009;73:572-6.

6. Rodríguez-Covarrubias F, Rivera-Ramirez JA, Gabilondo-Pliego B, Castillejos-Molina RA, Sotomayor M, Feria-Bernal G, et al. Tratamiento quirúrgico del carcinoma de células renales en personas de edad avanzada. Actas Urol Esp. 2016:40:395-9.

7. Zequi SC, Clavijo DA. The creation, development and diffusion of the LARCG-Latin American renal cancer group. Int Braz J Urol. 2017:43:3-6

8. Amin MB, Greene ES, Byrd DR, Brookland RK, Washington MK, Gershenwald JE, et al. AJCC Cancer Staging Manual. 8th ed. Berlin: Springer; 2017.

9. Dindo D, Demartines N, Clavien PA. Classification of surgical complications: a new proposal with evaluation in a cohort of 6336 patients and results of a survey. Ann Surg. 2004; 240:205-13

10. Van Poppel H, Becker F, Cadeddu JA, Gill IS, Janetschek G, Jewett M, et al. Treatment of localised renal cell carcinoma. Eur Urol. 2011;60:662-72
11. Volpe $A$, Jewett $M$. The natural history of small renal masses. Nat Clin Pract Urol. 2005;2:384-90

12. Ristau BT, Correa AF, Uzzo RG, Smaldone MC. Active surveillance for the small renal mass: growth kinetics and oncologic outcomes. Urol Clin North Am. 2017;44:213-22.

13. Droz JP, Boyle H, Albrand G, Mottet N, Puts M. Role of geriatric oncologists in optimizing care of urological oncology patients. Eur Urol Focus. 2017;3:385-94.

14. Lane BR, Abouassaly R, Gao T, Weight CJ, Hernandez AV, Larson $\mathrm{BT}$, et al. Active treatment of localized renal tumors may not impact overall survival in patients aged 75 years or older. Cancer. 2010;116:3119-26.

15. Tang DH, Nawlo J, Chipollini J, Gilbert SM, Poch M, Pow-Sang $\mathrm{JM}$, et al. Management of renal masses in an octogenarian cohort: is there a right approach? Clin Genitourin Cancer. 2017; 15:696-703.

16. Mirza M. Management of small renal masses in the older adult. Clin Geriatr Med. 2015:31:603-13.

17. Mir MC, Pavan N, Capitanio U, Antonelli A, Derweesh I, Rodriguez-Faba $\mathrm{O}$, et al. Partial versus radical nephrectomy in very elderly patients: a propensity score analysis of surgical, functional and oncologic outcomes (RESURGE project). World J Urol. 2020;38:151-8.

18. An JY, Ball MW, Gorin MA, Hong Jj, Johnson MJ, Pavlovich CP, et al. Partial versus radical nephrectomy for T1-T2 renal masses in the elderly : comparison of complications, renal function, and oncologic outcomes. Urology. 2017;100:151-7. 